\title{
Wireless: Will Wi-Fi Replace Cell Phones?
}

\author{
Dr. Chris Rose, (E-mail: crose@ triof.org), Technology Research Institute of Florida, Inc.
}

\begin{abstract}
Wireless cellular telephones are extremely popular, especially now that they incorporate text messaging and picture capabilities. At the same time the speeds of cellular networks keep increasing with the establishment of $3 G$ networks and the recent announcement of soon to be deployed $4 G$ networks which will have speeds up to 1.5 megabits per second. However, advancements in established 802.11 Wi-Fi mesh networking technology could overtake the cellular phone system by providing a more efficient and cheaper network while providing a faster, more flexible, more reliable and more useful network. Perhaps the idea of a Wi-Fi portable SIP phone, using VoIP, which is connected to the regular Internet at speeds up to 6 megabits per second and which can be used anywhere in the world where there is a Wi-Fi network might be more appealing to the consumer.
\end{abstract}

\section{Introduction}

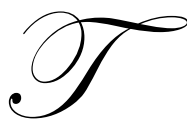

he future of wireless is believed by many to be dependent on the deployment of faster and more advanced wireless services. The Third Generation wireless (3G) will provide access, by means of one or more radio links, to a wide range of telecommunication services supported by the fixed telecommunication networks and to other services that are specific to mobile users. A range of mobile terminal types will be encompassed, linking to terrestrial and/or satellite based networks, and the terminals may be designed for mobile or fixed use (FCC.gov, 2002). The 3G service will support more than basic features like voice, email, text, notifications and Short Message Service (SMS) since they will support various applications which range from streaming video, multimedia and m-Commerce to file transfer (Komagan, 2000). Recently, Nextel announced that it would shortly begin testing of a new Forth Generation (4G) wireless network with speeds of up to 1.5 megabits per second which will enable high-speed wireless to desktops, notebooks and PDAs (Charny, 2004a).

\section{$3 G$ - Future of Wireless?}

Some researchers believe that the fate of the wireless Internet revolution may rest on the shoulders of consumers under age 25, and upscale users who will drive demand for $3 \mathrm{G}$, and marketers who focus on the youth and wealthy population segments will have the best chance of capturing the wireless Internet market. They believe that marketers can achieve this type of branded offerings by forming strategic alliances with businesses that provide networks, content, hardware and/or software. "For those marketers whose core competencies are in consumer insights, new product development and branding, the potential is huge and virtually untapped" (Greenspan, 2002).

Based on the collected data, it was determined that mobile phone penetration patterns do not follow regional or geographic boundaries and the devices are currently used most for voice and text message communication. Also, "consumers are lukewarm to the idea of WAP phones and 3G networks. However, users will give permission for $3 \mathrm{G}$ devices most readily in the communication and information areas followed by the financial applications of m-payments, m-banking, and m-trading. There also appears to be many niche applications, such as chat rooms, forums, etc." (Greenspan, 2002).

In 2002, Sprint, the fourth ranked U.S. mobile operator launched their network upgrade nationwide, saying it would provide average data transmission speeds of 50 to $70 \mathrm{kbps}$, with a peak rate of $144 \mathrm{kbps}$, which is comparable to the wireless data networks rolled out by Verizon Wireless, Cingular and AT\&T Wireless (Wrolstad, 2002). Although high-speed wireless has been somewhat successful in Asia "in the United States, at least, the need for full motion video on a screen slightly bigger than your thumb isn't readily apparent to most people... The 
wireless carriers are trying to invent applications for the wireless Internet, and I'm not sure they're the ones to do it. I don't know who it will be, but I'm pretty sure it won't be Sprint or Verizon or AT\&T Wireless that will figure out what applications are going to drive demand" (Moore, 2001).

Unlike 3G, the demand for WAP services can easily be determined. WAP, or Wireless Application Protocol, is the de facto standard for delivering such features as email and text messaging over wireless networks. As people become less attached to desks, they need access to information usually handled on PCs. While it would make sense for WAP services to succeed for this reason, they really haven't. Ease of use and display interface problems have not helped this technology. Charles Golvin, an analyst at Forrester Research, claimed that many of the problems associated with WAP would have been addressed by $2.5 \mathrm{G}$ technologies, which offer data rates of up to $53 \mathrm{~Kb}$ per second (Moore, 2001) but in reality it didn't.

\section{Mesh Networks}

This idea of a high speed wireless Internet nirvana that the third generation $(3 \mathrm{G})$ mobile phone companies have been promoting for years are just starting to be implemented, but a technology called mesh networking has the potential to actually deliver this type of network quicker, more effectively and more reliably than any of the mobile phone companies could. Two companies, US-based MeshNetworks and Moteran Networks of Germany, are each creating their own individual competing adaptation of mesh networking.

Mesh networking is an ad hoc peer-to-peer technology which is self-forming and self-healing so instead of the existing hub and spoke framework of wireless communications, wherein each device connects to an overloaded central antenna, any time a mesh enabled device (which can be mobile phones, PDAs or laptops) are close to each other, they automatically create a wireless mesh network. Every device in the area adds to the network and acts as a repeater or router, so each device relays network traffic for everyone else. Traffic hops from device to device until it reaches the nearest Internet access point, therefore this decreases the need for central antennas and improves wireless coverage. As the number of mobile phones increase, and wireless PDAs, laptops, and other devices begin to crowd the spectrum, this approach to wireless networking may be inevitable (Rojas, 2002). Since each mesh networking enabled device complements each other instead of competing with each other, this make for a more robust network therefore if one device fails, the network will remain operational unlike in a cellular network when, for example, a cell tower fails.

Mesh networks also have several other advantages over $3 \mathrm{G}$ wireless networks. While $3 \mathrm{G}$ operators offer mobile services that have connection speeds of up to $144 \mathrm{kbps}$, Moteran and MeshNetworks are able to offer connection speeds of up to 6Mbps. The technologies that mesh networks use include Wi-Fi, which is the emerging standard for high speed wireless networking, also known as 802.11. Because mesh networks use Wi-Fi, the equipment and infrastructure needed to create them is cheap and readily available, therefore instead of building cellular phone towers that often cost hundreds of thousands of dollars all that is really needed to implement a network are wireless access points strategically placed around town to relay traffic, and the proper software. Existing laptops and wireless PDAs can be mesh enabled by software.

Unlike with $3 \mathrm{G}$ cellular, the part of the spectrum that Wi-Fi operates on is unregulated in the US and Britain which also means that anyone could set up their own mobile phone network. The mobile phone companies are not very pleased about this state of affairs especially since many of them spent billions of dollars acquiring $3 \mathrm{G}$ licenses. The only things that are needed are very inexpensive relays and mobile phones equipped to connect to the network. More importantly, with every additional customer that becomes a part of a mesh network, coverage gets better instead of getting worse, as is currently the case with mobile phone networks (Rojas, 2002).The main wireless networking standard, $802.11 \mathrm{~b}$, is very popular and more importantly it is cheap and this could cause problems for carriers promoting $3 \mathrm{G}$ wireless telecommunications. According to analysts, the growing popularity of the $802.11 \mathrm{~b}$ networking standard could dramatically reduce consumer demand for third generation $(3 \mathrm{G})$ wireless networks. The fear is that Wi-Fi could lower $3 \mathrm{G}$ revenues by nearly a third and that could spell big trouble for $3 \mathrm{G}$ providers (Maier, 2002). 


\section{Integration and Convergence}

However a convergence of these networks is also possible and Qualcomm, which licenses cell phone designs to manufacturers and makes chipsets, is the latest company to begin incorporating cell phones with the WiFi wireless networks. Qualcomm has begun designing and selling cellular phone processors with Wi-Fi inside to keep abreast of the rest of the wireless industry, which is already selling such hybrid devices.

Because Wi-Fi networks can also carry voice calls, these networks could be used in the future to improve cell phone reception in buildings, where cellular coverage is traditionally poor, the wireless industry considers Wi-Fi a way to augment cell phone networks. Wi-Fi could also be used as one temporary method for carriers to meet the hype of so called $3 \mathrm{G}$, or third generation, wireless Web networks, which is an area on which they are currently concentrating. The carriers are promising a nationwide wireless network of much higher speeds which would make it simple, for example, to download music on a cell phone (Charney, 2002a).

Texas Instruments has introduced its Wi-Fi chips specially intended for mobile devices, such as cell phones and PDAs. These microprocessors address the two main concerns that mobile devices makers have about Wi-Fi, namely that it requires both a lot of power and big chips. The new microprocessors are about 44 percent smaller than the company's previous Wi-Fi chips (which were for laptop computers) and this will make them fit more comfortably inside the limited space of a cell phone or PDA. In addition, the new TI chips reduce power consumption tenfold since they are programmed to go into a low power stand by mode about 95 percent of the time.

Recently Nokia began to sell Wi-Fi phones and T-Mobile, which has added access to Wi-Fi networks, has motivated Texas Instruments into redesigning its chips. They had to make the chips small because there is limited room inside a cell phone and to be compatible with Wi-Fi networks, they also have to have a longer battery life so that the users would not have to charge or change their battery numerous times per day. TI has been very aggressive about introducing 802.11 into cell phones but so has Qualcomm, which intends to put Wi-Fi capabilities into some of the tens of millions of cell phone chips it sells every year (Charney, 2002b).

About 70 percent of the world's phones use an open standard called GSM (Global System for Mobile Communications) and these manufacturers have already created some hybrid products. BT, a carrier in the U.K., has begun offering a hybrid combination phone and wireless service. In the United States, AT\&T Wireless is said to be part of "Project Rainbow," an Intel led proposal to create a nationwide wireless Wi-Fi network (Charney, 2002a).

In addition, although Texas Instruments is already the world's biggest chip supplier for mobile phones, they also introduced a new processor. TI claims their new processor will handle the four basic mobile phone functions power management, transmission management, radio frequency and memory each of which currently requires its own chip. This new technology will require reducing the complexity of a cell phone down to one central processor and 25 passive components, from the current level of four chips and 180 passive components (Clarke, 2002).

However, Intel is emerging as a rival to Texas Instruments in the embedded chip market and has been working with Texas Instruments competitor Analog Devices. Intel has discussed plans for its Wireless Internet on a Chip, which will perform the same basic cell phone functions that Texas Instruments' upcoming chip will handle. The completely integrated wireless chip will eventually absorb technologies for Bluetooth, which links to nearby wireless devices; for $802.11 \mathrm{~b}$, to give wireless network access; and for GPS (Global Positioning System) satellite based location finding. With its single chip goal in mind, TI plans to offer a two chip system to mobile handset makers in 2003, with one chip for baseband transmission of radio signals and a second with a built in digital radio frequency converter (Reuters, 2002).

\section{Portable Wi-Fi SIP Phones}

Wi-Fi phones usually depend on Voice over IP (VoIP) and to use VoIP it is possible to simply download some software and then use your computer along with a microphone and speaker or obtains a dedicated Session Initiated Protocol (SIP) phone. Some of this VoIP software already comes with most computers, the most popular 
being Microsoft Messenger. However, Pulver Innovations introduced in late 2003 its WISIP, which is a wireless SIP phone which operates on standard $802.11 \mathrm{~b}$ wireless. It is the size of a cell phone and can make free phone calls wherever there is a Wi-Fi hotspot. Cisco systems recently also introduced a portable SIP phone although Cisco's phone depends on being in a PBX environment to make telephone calls. Therefore for example, if someone with one of these phones went into a Starbucks, or any other location with a Wi-Fi hotspot, they would be able to make free phone calls. Not only that, but their phone instantly assumes their original telephone number. For example, if someone who worked at a corporate headquarters in Miami, Florida and was assigned the telephone number (305)555-1234, and if he took his WISIP phone with him and walked into a Starbucks in Japan, Russia or France he would still be reached at the same number and be able to contact his home office in Miami as a local call. The cost to use the SIP phone would be the same as the cost of a regular Internet connection, which in many cases is free.

Portable Wi-Fi phones are also more secure than regular cell phones since it is extremely difficult to differentiate the voice bits from the trillions of other bits of information passing through the Internet at the same time. In fact, Jeff Pulver of Free world Dialup stated if he was ever forced by law enforcement agencies to wiretap one of his subscribers he would have to undertake a science project lasting a few months to see if it could even be done while others believe that the technology to tap into Wi-Fi calls has not yet been developed (Charney, 2004b). Some VoIP phones even use strong AES 256 bit encryption which makes eavesdropping virtually impossible.

Advances in the distance between 802.11 nodes have also increased tremendously and although most of these are experimental, they still rival the best of cell towers. Weber State University students in December 2003 demonstrated a connection, without amplification, across the Great Salt Lake, a distance of 82 miles. Although this was specially modified equipment, possibly under ideal conditions, it proves that 802.11 can be taken seriously as a medium to long range networking technology. This bodes well for the entire SIP phone industry.

\section{Conclusion}

The combination of inexpensive equipment and high data transmission speeds has made Wi-Fi especially popular with business customers. Yet this is the same demographic that wireless carriers are targeting with new $3 \mathrm{G}$ and $4 \mathrm{G}$ networks therefore Wi-Fi could be a serious threat. "Wi-Fi definitely has the ability to erode the revenue potential of 3G," says Michael King, an analyst for Gartner Dataquest. Alan Reiter, president of consulting firm Wireless Internet and Mobile Computing, agrees. "I think it's possible that $3 \mathrm{G}$ could suffer injuries from a thousand cuts as a result of Wi-Fi," he says. Ultimately, however, $3 \mathrm{G}$ and Wi-Fi should be able to coexist. "The technology is actually very complimentary, because they are not truly competitive technologies," King says. "I expect that mobile carriers will purchase some Wi-Fi providers, and we'll start to see some integration."(Maier, 2002). Maybe, this convergence is the future of wireless, but perhaps the continued the improvements in Wi-Fi networking might one day even make cellular obsolete.

\section{References}

1. Charney, B. (2002, August 30) TI shrinks its Wi-Fi chips. C-net News.com. Retrieved from the World Wide Web on February 15, 2004 from http://news.com.com/2100-1033_3-956109.html

2. Charney, B. (2002, July 30) Qualcomm to add Wi-Fi to phone chips. ZDnet.com. Retrieved from the World Wide Web on February 15, 2004 http://zdnet.com.com/2100-1105-947121.html

3. Charney, B. (2004a, February 6) Nextel to test ' $4 \mathrm{G}$ ' broadband service. C-net News.com. Retrieved from the World Wide Web on February 13, 2004 from http://news.com.com/2100-1034-5155050.html

4. Charney, B. (2004b, February 13) VoIP: It's not so easy to listen in. C-net News.com. Retrieved from the World Wide Web on February 14, 2004 from http://news.com.com/2100-7352_35159159.html?tag=nefd_top

5. Clarke, P. (2002, September 5) TI plans to implement 'single-chip' cell phone in 2004. Semiconductor Business News. Retrieved from the World Wide Web on February 15, 2004 from http://www.eetuk.com/tech/news/OEG20020904S0032

6. Federal Communications Commission - FCC (2002) Third Generation Wireless Systems. Retrieved from the World Wide Web on February 15, 2004 from http://www.fcc.gov/3G/ 
7. Greenspan, R. (2002, May 24) Youth and Upscale Consumers Want an M-Lifestyle. CyberAtlas. Retrieved from the World Wide Web on February 15, 2004 from http://cyberatlas.internet.com/markets/wireless/print/0,10094_1144611,00.html

8. Komagan, C. (2000, June 30) Wireless 3G: The Future of Wireless. AllNetDevices. Retrieved from the World Wide Web on February 15, 2004 from http://www.allnetdevices.com/developer/white/2000/06/30/wireless_3g.html

9. Maier, M. (2002, March 12) Will Wi-Fi rain on the 3G parade? Business2.0. Retrieved from the World Wide Web on February 15, 2004 from http://www.business2.com/b2/subscribers/articles/0,17863,531580,00.html

10. Moore, J. (2001, May 31) 3G and WAP making slow progress. Business2.0. Retrieved from the World Wide Web on February 15, 2004 from http://www.business2.com/b2/subscribers/articles/0,17863,530233,00.html

11. Rojas, P. (2002, August 29) Making a mesh on the move. The Guardian. Retrieved from the World Wide Web on February 15, 2004 from http://www.guardian.co.uk/Print/0,3858,4489999,00.html

12. Wrolstad, J. (2002, August 8) Sprint Launches Next Generation Wireless Network. News Factor Network. Retrieved from the World Wide Web on February 15, 2004 from http://www.wirelessnewsfactor.com/perl/story/18943.html 
Notes 